\title{
PAIN AND THE ETHICS OF PAIN MANAGEMENT
}

\author{
REM B. EDWARDS \\ Department of Philosophy, College of Liberal Arts, University of Tennessee, Knoxville, TN 37996, U.S.A.
}

\begin{abstract}
In this article I clarify the concepts of 'pain', 'suffering', 'pains of body', 'pains of soul'. I explore the relevance of an ethic to the clinical setting which gives patients a strong prima facie right to freedom from unnecessary and unwanted pain and which places upon medical professionals two concomitant moral obligations to patients. First, there is the duty not to inflict pain and suffering beyond what is necessary for effective diagnosis, treatment and research. Next, there is the duty to do all that can be done to relieve all the pain and suffering which can be alleviated. I develop in some detail that individuality of pain sensitivity must be taken into account in fulfiling these obligations. I explore the issue of the relevance of informed consent and the right to refuse treatment to the matter of pain relief. And I raise the question of what conditions, if any, should override the right to refuse treatment where pain relief is of paramount concern.
\end{abstract}

In the clinical setting. medical personnel must constantly act upon some ethics of pain management. Such questions as "Is the patient in pain?" and "What can and should we do about it?" cannot be evaded by doctors, nurses and other support personnel who must daily live face to face with the bitter reality of human injury and illness and their attendant pains. What does a mere philosopher have to contribute to a discussion of the ethics of pain management? Although medical professionals obviously do so much to help, it may seem at first that philosophers have little or nothing to do with the bitter realities of human suffering. However, pain is a topic of universal human interest, and no one has a monopoly on the topic. Historically, philosophers have been keenly interested in the topic of pain and have much worthwhile to say about it, as I expect to show.

One legitimate task of philosophy, most agree, is the clarification of concepts. In the clinical setting, when we ask: "Is the patient in pain?" and "What can and should we do about it", how often do we also ask "What do we mean by "pain"?" This question is too seldom posed, and I suspect that many patients are being neglected in our medical institutions partly because we attempt to fulfill our personal and professional responsibilities to suffering humanity without a very clear and sufficiently general concept of pain. Perhaps here philosophy can help. It was Epicurus who wrote centuries ago that "Vain is the word of a philosopher which does not heal any suffering of man. For just as there is no profit in medicine if it does not expel the diseases of the body, so there is no profit in philosophy either, if it does not expel the suffering of the mind" [1].

\section{PAINS OF BODY AND OF SOUL}

Almost all of the most important Greek philosophers discoursed and wrote extensively upon the topics of pleasure and pain. though only the latter is our present concern. Epicurus. Aristippus, Plato and Aristotle and innumerable later philosophers have recognized an important difference between two different classes of pains, variously characterized on the one hand as physical, sensory or bodily, and on the other hand as mental, spiritual, non-sensory or psychological. Typical examples of bodily pains are those derived from bodily lesions, infections, cuts, bruises, burns, cramps, broken bones, headaches, toothaches, stings, etc. Typical examples of mental pains are those disagreeable feelings involved in depression, anxiety, uncertainty, guilt, grief, boredom, sadness, sorrow, fear, anger, alienation, loneliness, etc. A number of different ways of differentiating conceptually between these two classes of pains have been attempted [2], but I am convinced that the most adequate way to do it is along phenomenological lines. In my recent book, Pleasure and Pains: $A$ Theory of Qualitative Hedonism 1 develop and defend the thesis that the so-called bodily pains are those which are given to immediate subjective experience as being located in some fairly definite place or region of the body. In the grips of localized bodily pain, when the doctor asks us "Where does it hurt?" we do not need a sophisticated body-mind metaphysics, or an intimate knowledge of anatomy or neurology to answer his question. On the other hand, when we are experiencing the very real and highly objectionable 'pains of soul' on our list, the question "Where does it hurt?" has no clear meaning [3]. Bodily pains are those which are immediately experienced as having bodily locus, whereas spiritual pains are those which are immediately experienced as non-localized, as having no specific bodily place. This is purely a phenomenological distinction and does not commit us in any way to any controversial theses in metaphysics, etiology, or neurology. On this analysis, the so-called 'psychogenic pains' felt as having bodily locus by the hysteric would count phenomenologically as bodily pains, as would the phantom limb pains of the amputee and all so-called 'referred' and 'psychosomatic' pains. We must also recognize that mental pains are often accompanied by bodily pains. As Rollo May has writien:

acute loneliness seem to be the most painful kind of anxiety which a human being can suffer. Patients often tell us that the pain is a physical gnawing in their chests, or feels like the cutting of a razor in their heart region, as well as a 
mental state of feeling like an infant abandoned in a world where nobody exists [4].

From my reading of contemporary studies dealing with current psychological and medical research on the topic of pain, it appears that attention is now being paid primarily to localized bodily pain. Even where causal connections between localized bodily pain and the non-localized pains of anxiety, uncertainty, guilt, loneliness, depression, etc. are acknowledged, the latter are usually not being called 'pain'. There are a few interesting exceptions, however. For example, in the case of Mrs Abel, the cancer patient studied so extensively by Fagerhaugh and Strauss, we are told that at one point the nurses "had really begun to question the amount of emotional pain and the amount of physical, organic pain" that she was suffering [5]. A nurse working on a geriatric ward is reported to have said that "We have not so much physical pain as the pain of loneliness" [6]. When a patient is told by a doctor that he is dying, "the announcement ... usually leaves the patient very depressed. To cope with this initial response, the nurses stand by with medication to relieve emotional as well as physical pain" [7].

Innumerable examples of a usage of the word 'pain' sufficiently broad in scope to include mental as well as bodily discomforts could be produced from the writings of philosophers, doctors and nurses, psychologists and plain men. The main reason why 'pain' is narrowly used to cover only localized discomfort in contemporary research studies seems to be that this variety of pain can be easily and cheaply produced in the laboratory setting without serious danger of permanent injury, by such simple techniques as applying and gradually increasing electricity, pressure, cold, heat, pin pricks and pinchesall with a minimum of legal and ethical restraints. It is much more difficult experimentally to induce acute depression, anxiety, fear, guilt, loneliness, boredom, etc., though this is by no means impossible. The real problem here is that we commonly acknowledge that it is much more questionable ethically to generate such pains of soul, and this says something very important about the relative disvalues which we tend to attach to these two classes of disagreeable feelings. We realize at least implicitly that the disagreeable feelings in these two classes are qualitatively distinct and that they also differ significantly in intrinsic disvalue, acute non-localized pains being of greater disvalue somehow than equally acute localized ones. If this is recognized in the laboratory setting, the application to the clincal setting should be obvious. The imperative to assist the patient in gaining relief from the unnecessary mental pains arising from his illness should be at least as strong as, if not stronger than, the imperative to assist in the relief of unnecessary bodily pains. Yet, it is precisely in this area that there seems to be the greatest patient neglect.

It is theoretically possible to produce a general definition of 'pain' which covers both the nonlocalized and localized varieties. In my Pleasures and Puins, I define 'pain' in the generic sense as any quality of feeling which we ordinarily desire to eliminate or avoid for its own sake [8]. Both localized and non-localized disagreeable feelings qualify as pains under this definition. This broad concept of pain is perfectly compatible with our usual willingness to accept pains which are seen as necessary instrumentally for the achievement of our long range goals, and with our attempts to endure with dignity those pains which are unavoidable no matter what anyone does to help. The acceptance of necessary pains is in no way incompatible with the value judgments that both necessary and unnecessary pains are intrinsically bad. worth avoiding for their own nasty sake, even when the necessary ones must be endured.

The broad usage of the word 'pain' to cover both phenomenologically localized and non-localized disagreeable feeling has been fairly commonplace among philosophers from the time of the ancient Greeks. In philosophy, this broad usage has been governed by a theoretical interest in having a word which will identify and include all those disagreeable feelings which it is reasonable to want to avoid and eliminate for their own nasty sake where at all possible, especially when they make no identifiable contribution to our long range personal plan of life. Although I am no etymologist, it may (and it may not) [9] be true that originally 'pain' applied only to the localized varieties of disagreeable feeling and that the broader usage was a metaphorical extension of this. Linguistic innovations eventually can become established usage, and thousands of years of the broaded usage for 'pain' should make for a real convention even from the standpoint of ordinary language. There is surely some truth in Ivan Illich"s insistence that "The technical matter which contemporary medicine designates by the term 'pain' even today has no simple equivalent in ordinary speech. In most languages the term taken over by the doctors covers grief, sorrow, anguish, shame and guilt" [10]. Those accustomed to speaking plain English will find nothing illegitimate or even confusing about the broad usage which I am recommending. I further recommend it because I believe that much actual harm and neglect to patients results from restricting 'pain' to 'bodily pain', for it frequently happens that a patient's suffering is dismissed as 'psychological', 'imaginary' or 'unreal' when it is thought not to be bodily localized in nature [11]. Mental hospitals. which deal primarily with pains of soul, are the most under-funded medical institutions in our society, partly because we share the misconception that the non-localized pains of mental patients are somehow illusory. Those who believe that pains of soul are somehow unreal also find it easy to convince themselves that the ethics of pain management does not apply to that kind of suffering.

Lest it be suspected that my primary purpose thus far has been merely to promote a new or broader word usage for 'pain', let me make it clear that I really do not care what terminology we choose to adopt so long as we recognize that those intense and prolonged disagreeable feelings involved in depression, anxiety, guilt, fear, alienation, loneliness, uncertainty, monotony, etc. are great intrinsic evils and that those who deal with the sick and injured have just as much a moral obligation to help patients cope with these as with localized bodily discomforts. Often the expression 'pain and suffering' is used to differentiate between the two classes of pain which I 
have distinguished, though there is a certain redundancy here in that "suffering" includes both types of pain. However, if we are more comfortable with such terminology then so be it. If we do choose to talk that way, let us be sure that once we ask "Is the patient in pain?" we immediately add "and is he or she suffering?" Suffering in this sense is as real as and often worse than pain. Unless this is acknowledged, professional responsibilities in the area of managing those unnecessary intrinsic disvalues directly generated by injury and disease will likely not be fulfilled. Without repeating any of the gruesome details, it seems to be that the wide prevalence of this sort of patient neglect is amply documented and illustrated in virtually every chapter of Politics of Pain Manage. ment by Fagerhaugh and Strauss [12].

\section{INDIVIDUALITY AND THE ETHICS OF PAIN MANAGEMENT}

Once we have decided that a patient is in pain and/or suffering", there is a broadly based humanistic ethics which applies to the domain of medical care which gives patients a strong primu facie right to freedom from unnecessary pain, and which places upon medical professionals two concomitant moral obligations to patients. First, there is the duty not to inflict additional pain and suffering beyond what is absolutely necessary for effective diagnosis, treatment and research. Next, there is the duty to do all that can be done within the limits of current medical knowledge and available resources to relieve all the pain and suffering which can be alleviated. Attempts to fulfill these obligations must be subject to the informed consent of the patient and must be compatible with the goal of an ultimate restoration to health where there is hope of a cure, or with the patient's own plans and desires for living and dying where there is no such hope, or with conditions to be discussed later that properly override the patient's preferences. I shall not explore the theoretical foundations of these rights and duties, though I will say that they can be derived in one way or another from almost every major philosophical theory of ethics available to us. In that sense they are broadly justified.

A few careless, incompetent or sadistic medical professionals may occasionally violate the duty not to inflict unnecessary pain, but I wish to concentrate mainly upon the duty to help relieve unnecessary pain (for short). This duty is widely infringed, and some of the most interesting problems pertaining to the ethics of pain management arise in connection with it.

Persons who recognize a duty to help relieve unnecessary pain must have a workable solution to the problem of knowing other minds. In the philosophy seminar room, this is an ancient academic problem which may be endlessly debated without significant outcome; but in the clinical setting the question is far more than merely academic. If we accept the obligation to help relieve the unnecessary pains of others we must be able to determine with reasonable accuracy not only that the other is suffering but aiso the quality (kind) and the quantity (intensity and duration) of the pain involved. Many of the practical disagreements about what to do for the suffering patient and when or whether to do anything spring from different assessments of the kind and degree of pain being experienced.

Since only the patient knows his pain directly, others who would give him aid must somehow solve the problem of the connection between subjective pain experience and objective pain expression. Every hospital contains its share of excessive expressers, average expressers and below average expressers of pain. Average expressers are usually easily managed and cause little trouble or consternation for the staff; but enormous headaches and heartaches are created by those excessive expressers that I shall call 'epicureans" [13] who may become the "patient of the day-or the week-or the month" [14] and by the under average expressers who are commonly labeled by the philosophical term "stoics" even in the clinical setting.

Clinical decisions about whether and when to give more drugs or to use other techniques of pain relief turn upon staff assessments of the kind and degree of pain being experienced. It is at this point that a 'political' or ethical struggle for pain relief is generated between patient and staff. With good reason, we commonly refuse to make a simple and direct correlation between kind and degree of pain expression and kind and degree of experienced pain. We know that pain expression may vary with such things as cultural upbringing, individual differences in verbal and other expressive skills, individual assessments of what is and is not socially expected and appropriate, and individual moral and religious standards of behavior. Deliberate attempts at deception must also be distinguished from the 'real thing' somehow. After proper allowances have been made for all these factors, one additional variable must be assessedthe natural variations from individual to individual in susceptibility to pain. This may be both the most significant and yet the most neglected of all the variables which affect our judgments concerning the correlation between experienced pain and pain expression.

Some very exciting and promising research concerning natural individual variations in susceptibility to pain has been done by Asenath Petrie and her associates at Harvard Medical School and reported upon in her book entitled Individuality in Pain and Suffering. Petrie began with the following problem, as she describes it: "I had been puzzled by the observation confirmed by numerous physicians and nurses that the same trauma affected people so variously. It seemed unlikely that these contrasting reactions to pain were based solely on differences in the control demanded by the culture or by the individual himself" [15]. Petrie claims to have discovered, "a neurological or physiological basis for this variation in tolerance for pain" [16]. As a result of her extensive research, Petrie was able to distinguish three types of people who differed significantly in the ways in which they naturally 'modulated' both sensory experience and pain experience. She called these "the reducer, the augmenter, and the moderate" [17]. By definition, "The reducer tends subjectively to decrease what is perceived; the augmenter to increase what is perceived: the moderate neither to reduce nor to aug- 
ment what is perceived" [18]. Under carefully controlled and repeatable experimental conditions, a tendency to amplify or decrease subjectively experienced pain caused by the 'same trauma' was found to be correlated definitively with the tendency to amplify or decrease tactile stimuli in other sensory modalities. With respect to tactile stimuli this is easily measured by allowing the blindfolded experimental subject to estimate with one hand the size of a block of wood previously held in the other hand. Pain augmenters were found to be size augmenters, pain reducers were size reducers and pain moderates were size accurates [19]. Weight and sound amplification and reduction may also be experimentally correlated with this [20]. Other important correlations were experimentally established which should be of great significance for those struggling with the ethics of pain management. Brain surgery in the prefrontal areas of the brain converts augmenters into reducers [21]. Augmenters are much more concerned with 'the signs and symptoms of ill health' than reducers [22] and consequently are more easily persuaded to take precautions against injury and avoid such health endangering activities as smoking [23]. Reducers are more likely to suffer intensely from those 'mental' distresses correlated with sensory deprivation such as monotony [24] and "restlessness and loss of feeling of identity and loss of contact with reality" [25]. They greatly prefer physical punishment to solitary confinement and other forms of social isolation [26] and they will inflict bodily pain upon themselves if no other way can be found to alleviate the stress of monotony [27]. In the clinical setting, they endure localized bodily pain extremely well simply because they experience much less of it than the typical moderate or the super sensitive augmenter, but they are also the ones who will suffer the most (both from monotony and loneliness presumably) from the social isolation, confinement, and enforced inactivity usually imposed upon them in the clinical setting [28]. On the other hand, augmenters will be most susceptible to localized bodily pain because they are equipped by nature to experience more of it, but their compensation is that they will suffer the least from sensory deprivation [29]. Without being susceptible to loneliness and monotony, they will be even more susceptible to the mental pains of anxiety and depression [30], both of which are associated with the introverted personality typical of the amplifier [31]. By contrast, the reducer will be an extrovert who is physically more active [32] and who requires considerably more sensory stimulation derived from such sources as contact sports, movement, speed, etc. [33] than the moderate or the augmenter. The introverted augmenter will be more interested in books and ideas and will make better grades in school [34]. He will also typically need fewer but deeper friendships than the reducer who needs a greater variety of more superficial but active social contacts [35]. The augmenter will be keenly sensitive to the sufferings of others, but not the reducer who "cannot empathize adequately with experiences that he does not share. The extreme reducer fails to understand suffering with pain and may inflict it with little compunction" [36]. On the whole, the augmenter enjoys a richer inner life than the reducer [37].
I have summarized some of the more interesting findings and correlations which Petrie and her associates have been able to establish, but there are many others which I have not covered [38], including her verdict that there are great individual variations in responsiveness to pain control medications and therapies. If it should be true, as her work seems to show, that there are significant natural differences between individuals with respect to their susceptibility to different kinds and degrees of suffering and their responsiveness to relief measures, what differences should that make with respect to the duty to help relieve unnecessary pain and suffering?

\section{Epicureans}

Although I do not claim to have all the answers by any means, certain conclusions seem to be obvious First of all, we cannot succeed in the project of pain relief without taking the individuality of the sufferer fully into account. Next, we must recognize that we cannot succeed in this project as long as we continue as usual to judge all patients by the standard of average or moderate sensitivity and responsiveness The credibility of the patient's pain expression is challenged all too often because he makes atypical claims to pain experience and makes atypical demands for pain relief-with little or no attempt to determine whether he is a natural pain augmenter, moderate or reducer. If he should be an augmenter, his needs may indeed be super normal and his above average expression of pain behavior may be perfectly appropriate. The seemingly inordinate demands which he makes for staff time and attention and relief measures may be completely justified. This could be true especially in light of the fact that localized bodily pains and non-localized fears and anxieties tend to feed upon and amplify one another. One of the most successful techniques available to us for the reduction of bodily pain involves helping the patient to reduce his pains of soul, and one of the commonest areas of patient neglect lies in our failure to give such aid

Furthermore, a common area of patient abuse consists in staff activities designed to generate pains of soul. Challenging the patient's claims concerning the degree of his suffering and/or his need for help definitely and gravely affects his moral standing in the hospital and broader human community. Such a person is tacitly branded as a liar, and he also comes to be regarded as somehow cowardly, uncooperative and lacking in will power or attention power. Consequently, he is relegated to the inferior status of being a defective moral agent. He may come to be labeled as 'difficult', 'demanding', a 'clock watcher', 'crock', 'malingerer' or 'manipulator'. He has what Fagerhaugh and Strauss call a "spoiled identity' [40]. ' $\mathrm{He}$ is addicted' may be uttered about him with varying degrees of contempt [41] and overly expressive patients may be stereotyped as 'paranoid' or 'schizophrenic' [42]. Once the proper degradation ceremony has been performed, staff members then feel morally justified in stereotyping and humiliating the patient, disregarding his pain professions and pleas for help, avoiding his room, ignoring his buzzer. and generally ostracizing him from the community of human moral agents. All these responses are designed 
to cause the patient to suffer from various pains of soul.

This sort of thing does little to enhance and much to destroy the patient's own feelings of self-esteem. Feelings of worthlessness, humiliation, guilt, fear, powerlessness, alienation, abandonment, etc. are likely to ensue. Medical professionals then become inflictors of pain rather than pain relievers. This is not to say that staff disapproval and rejection of patients is always unjustified, for there doubtless are just as many liars and connivers in our hospital beds as there are in the general population at large! But it is to say that great caution must be exercised in this area, and that the degradation activities of staff members must be carefully monitored for patient abuse. It is in dealing with genuine pain augmenters that the potential for such abuse seems to be greatest; and the case of Mrs Abel, the cancer patient studied by Strauss [43] and Fagerhaugh, seems to illustrate this point quite well. Some persons are just natural Epicureans who are super sensitive to suffering, just as others are natural Stoics who are unusually insensitive. We must now give some attention to the latter.

\section{Stoics}

It is often pointed out that the values of medical staff members deeply affect the quality and quantity of care that they are willing and able to give. If they attach great value to courage, cooperativeness, resignation and will power, they are very likely to deny moral standing to those patients perceived as failing to measure up to these stoic values. Furthermore, they are very likely to grant special moral standing and professional and personal favors to those stoical palients who are perceived as exemplifying courage, cooperativeness and strength of will. Now I do not wish to knock will power, but I would suggest that even here we ought to try to keep track of the distinction between natural pain augmenters, moderates and reducers. If enduring suffering with stoical determination and resignation entitles some patients to special esteem if not favoritism, we must at least distinguish between the pain reducer who is the natural stoic who effortlessly seems to exemplify the qualities of determination and resignation simply because he is actually doing very little suffering, and the moral stoic who through great effort of will actually manages to display these admirable qualities.

What are our moral duties in the medical setting to the stoical patient? First, let us recognize that even the natural stoic can and does suffer, though considerably less than what we would expect of a moderate or amplifying patient. When he makes his occasional requests for help, his suffering does activate the obligation to help relieve unnecessary pain. We should further recognize that he is particularly vulnerable to the soul pains of monotony and loneliness even when he experiences little bodily pain, and we should take appropriate measures to help him cope with them. Next, let us recognize that the moral stoic may be suffering a great deal more than we are led to suspect. Yet he is enjoying certain partially compensating secondary gains or satisfactions from the very effort of courage and will power which he is making and from his sense of being-true to his moral andior religious ideals. Understanding this much about him, we might wonder if we have a duty to offer him medication and whatever means to relief we have available. Most of us would agree, I suspect, that we at least have a duty to ask him regularly if he wants help, for we are deeply embarrassed and troubled by the story told by Fagerhaugh and Strauss of

the woman who suddenly demanded to sign herself out because for three days she had not been given any pain medication. although she had a prn order. The nurse who described the transformation of this initially pleasant, placid patient was perplexed: "We didn't know she was in pain; we werc waiting for her to ask" [44, p. 122]

Although waiting around for the stoic to ask for medication is much too passive, we might still wonder just how active the medical staff should be in encouraging the patient to accept pain relief measures. My own judgment is that they should never be so active that they actually coerce the patient into violating his own deepest moral and religious norms, for the net result of that will be insufferable pains of soul such as a deep erosion of self-esteem and an influx of overwhelming guilt. This will be worse to and for the patient than any bodily pains he can endure while he regards them as endurable.

\section{Paternalistic stoicism}

One of the most interesting moral problems to arise in connection with stoicism in the clinical setting is as follows. Do medical professionals have an obligation to try to instill the stoic values of courage, determination and resignation in patients who lack them? There is no doubt that staff members do in fact often require their patients to try to acquire and exemplify these prized traits of character. As Fagerhaugh and Strauss point out, the nurse often tells the patient: "The doctor says you can have the medication in three hours, but why don't you try to wait awhile"; and a demanding patient is assigned to staff members who are able to "set limits and treat him firmly, like a child". [45, p. 121]. "Nurses will admit that they are more sympathetic with the teeth-gritters than with the overly expressive patients" [46, p. 122].

Now, being something of a natural and moral (i.e. by reflection and choice) epicurean myself, I have always had my doubts about stoics, whether they be natural or moral-especially those who try to force us epicureans to be stoics against our will. This is especially true where no questions of immediate or long range health and happiness are at issue. Epicureans, to be sure, can and normally do attach a great deal of significance to the inherent satisfactions of courage, resignation and effortful self-control; and they can be persuaded of the long range utility of such virtues for the avoidance of future pain. But once they have arrived at an informed decision that enough is enough, should we then still insist that they exemplify courage and resignation just for their own stoic sake? I for one have may doubts

Aristotle noted that we cannot practice the moral virtues unless the proper conditions necessary for their realization are provided. Suffering does seem to be an essential condition for the actualization of certain forms of courage, determination and resignation, and perhaps for other moral and spiritual values 
as well. This being the case, we may ask what exactly are the limits of the duty in the medical setting to promote those values which may be actualized only through suffering, especially when this duty may come into conflict with the recognized obligation to help relieve unnecessary suffering. This is no moot point, for there are prominent authors who castigate medical professionals for their efforts to relieve suffering on the grounds that they are thereby depriving their patients of the opportunity for spiritual or moral growth and responsibility. For example, both Ivan Illich [47] and Victor Frankl [48] have intimated that medical personnel have a duty to refrain from providing their patients with drugs and other technological fixes for pain because doing so somehow interferes with the patient's chances for moral or religious self-realization through suffering. It is nevertheless extremely difficult to get from such moralists of medicine any precise answer to the question of what the duties of medical personnel are to their patients in that area in which the duty to relieve suffering comes into conflict with the ideal of soul making. A number of distinct positions are possible, even if we grant that some suffering is necessary for moral and spiritual self-realization.

First of all, there is the extreme position that instead of relieving suffering, we actually ought to infict it so that others might grow. Nietzsche justly ridiculed such a stance when he wrote:

If we admit, for example, the truth of the doctrine of Schopenhauer (but also of Christianity) concerning the redemptive power of suffering, then it becomes regard for the 'general welfare' not only not to lessen suffering, but perhaps even to increase it-not only for oneself but aiso for others. Pushed to this limit, practical ethics becomes uglyeven consistent cruelty to human beings [49].

I suspect that even the staunchest Stoic and Calvinist will balk at such cruelty, and I am convinced that this extreme position will be rejected by all humane and reflective persons. There should be some important differences between a modern doctor and a medieval inquisitor.

Next, there is the position that even if we should not inflict suffering, there is at least a duty not to relieve any suffering so that the sufferers may grow in stoic and other religious virtues. I hope that even this position will be too strong for our reflective equilibrium; but if not, then we ought at least to agree that doctors and nurses who subscribe to it should be required to publicize their value commitments, now that doctors may advertise. We may imagine such newspaper ads as: "J. Calvin, M.D., General Practitioner: I let you suffer for your own good"; or "Illich, Epictetus and Frankl, Gyn. and Obs., We treat Stoics: Epicureans need not apply". As an Epicurean, I certainly would not want to patronize such physicians.

Finally, there is the position that there is at least a medical duty not to relieve some pains of soul or body so that self-realization through suffering may take place. Notice that we are talking about paternalistic situations where soul making through suffering is the sole reason for allowing suffering, not about those situations in which the rational epicurean could be persuaded to suffer as a necessary means to some important personal goals of his or her own Even in the latter cases, doctors and nurses may have a selling job to do; but when they fail, should they ever appeal to their own stoic values and allow some suffering solely for soul making purposes? If so. which particular sufferings and what degree of them should they allow? Only God could solve such problems, I suspect. I again hope that this modest obligation would not be embraced by mere mortals. It seems to me that even after we have done our best to relieve unnecessary and unwanted suffering, sufficient pain will always remain for nurturing the soul. In this world of woe, God, Mother Nature, The Devil, Fate or whatever you want to call it, can be relied upon to bless patients with all the anguish they require for soul making, especially when such anguish serves no rational purposes of their own. Medical professionals should leave this kind of paternalistic soul making through suffering in the hands of God. Their duty is to relieve tractable suffering when it serves no goals which their patients cannot be persuaded rationally to adopt as their own, i.e. no purposes to which they do not give their voluntary and informed consent

The question of whether suffering should be allowed to take place for soul making purposes should not be confused with the question of whether there might be other reasons for not attempting to relieve some pains of soul. Consider the commonplace practice of attempting to subdue with tranquilizers the grief of a person who has just lost a loved one. That such grief is not inherently desirable may be seen in many ways. We could agree that it would have been better for the loved one not to be lost at all, or that we should leave it to God and not to ourselves to inflict such grief, or that we should think of Heaven as a place where there will be no more such painful separations. We should not inflict grief that others might grow, but grief often seems inescapable in our world of woe, given our psychological constitution. If tranquilizers actually provide an escape from the inescapable, then they should be used. However, there is grave factual question about whether they really are effective in the long run. Grief will out in one way or at one time or another, so it seems. If it is not expressed and discharged immediately following the loss of an object of deep affection, repressed grief will likely be psychologically incapacitating in some frustrating respects until at some later time it erupts with even greater violence. These later expressions of grief are even more difficult to deal with hecause they occur at socially inappropriate times when those who would give social support and comfort during a normal period of grief are no longer available. If, as it seems, there is no way to avoid doing our grief work, then doing it immediately following a loss seems to be the lesser of the evils. Administering tranquilizers falls on the side of the greater of the evils, not because it interferes with soul making, but because in the long run it creates more pains of soul than it eases. Thus, they should not be used to subdue grief.

\section{INFORMED CONSENT AND REFUSAL}

Now I would like to make a few concluding remarks about a principle which is now generally 
regarded as one of the most fundamental principles of medical ethics, the principle of voluntary informed consent. The relevance of this principle to the topic of pain management has been much too little explored. I earlier noted that attempts to fulfill the obligation to relieve unnecessary pain should be subject to the informed consent of the patient. Now we must confront this qualification. I shall not explore in any depth the question of the theoretical foundations of the informed consent principle, though I will mention that it is deeply rooted in the significance attached to the dignity and autonomy of the individual in democratic societies, and to the fact that loss or lack of control over our destiny through the tyranny and coercion of others generates some of the most insufferable pains of soul that persons can ever suffer. For medical professionals, the selfprotective interest in avoiding prosecution for malpractice or for assault and battery is also pertinent here.

The principle of voluntary informed consent as applied to the competent adult person says that it is wrong to subject any such person to diagnostic, therapeutic, or experimental medical procedures to which he has not knowingly and freely consented. This principle places upon medical personnel the duty to give patients adequate information about the nature of such procedures, their probable risks, benefits, costs, consequences, alternatives, etc. and the duty to obtain the consent of the patient without undue influence, threat, incentive, or coercion. It logically implies a strong prima facie right to refuse any medical procedure to which the patient has not freely given his informed consent. In democratic societies, this principle now has the status of law as well as the support of broadly based moral conviction.

It is very understandable that many medical professionals find it hard to accept and apply the principle of informed consent. This is so partly because of difficulties in determining how much information they need to supply and an unwillingness to expend the time and effort required to supply it. The principle also requires them to cease being paternalistic and to give up the long cherished attitude that the doctor aiways knows best'. This attitude is usually justified concerning knowledge of the means to medical ends, but it is not valid with respect to the choice of the ends themselves. Here patient input is essential and should be the last word where none of the overriding conditions which I shall mention shortly obtain. At any rate, there is a great need for a clear answer to the following questions: Just how much autonomy in controlling the means to pain management and relief should be placed in the hands of the patient? Correspondingly, how much paternalism in this matter should doctors and supporting staff be willing to surrender?

One sphere where practical decisions are greatly affected by how we answer such questions is that of allowing chronic pain patients to have more control over the administration of pain control medication. Most of us want to acknowledge paternalistically that some limits have to be placed on patient control in the interest of avoiding addiction, and most of us recognizing that even this matter less and less as death draws nearer and nearer. We should recognize as well that the anxieties generated by being totally at the mercy of others with regard to the means of pain relief are often overwhelming and that these anxieties tend to magnify the very pain itself (localized) that needs to be eased. The other side of this coin is that such anxieties and amplifications may be largely avoided by allowing the patient to make his own properly informed decisions concerning the quantity and timing of pain relief medication. The possibility of patient abuse in this area is considerably less than many have feared especially since being in control diminishes pain. Where overmedication is a problem, we should take a careful look at the value laden concept of 'overmedication', which means: too much medicine-in relation to whose goals or values?

Giving patients more control over the means to pain relief becomes a very urgent issue where life and death are at stake. In applying the principle of informed consent and the corresponding right to refuse treatment to competent adult patients overwhelmed by pain, we might ask whether they would apply with different degrees of force to: (1) those whose death is imminent and who would prefer to die even sooner rather than submit to additional painful medical procedures or to prolonged and intense intractible pain generated by the injury or illness itself and (2) those who are in no imminent danger of death if treated, but who refuse to endure those natural and iatrogenic pains of body and soul which they must endure if they continue to live.

For patients in imminent danger of death, the choice of death has always been an effective means to the end of pain relief. Robert $M$. Veatch has pointed out that the first legal decision made in the United States respecting the right to refuse treatment was made in just such a case. In 1971 Mrs Carmen Martinez, a seventy-two-year-old Florida resident, was dying of hemolytic anemia. "Medical science... could not provide a cure, but it could offer continual transfusions to prolong the dying process. To facilitate the blood transfer, Mrs Martinez's veins had to be opened surgically in a process doctors called 'cutdowns'. 'Please don't torture me any more', she begged". The courts at first judged her to be incompetent, but then her daughter who had been appointed her guardian "also begged the judge, "No more cutdowns"". As Veatch characterized the judge's final decision, "A compassionate judge ruled for the first time in American legal history that the medical system may and must honor the daughter's demand that the torture be stopped" [50]. Untreated, Mrs Martinez died within twenty-four hours. I suspect that most of us would agree with this judge's decision, but in this sort of case the woman's age and the proximity and inevitability of her death probably has a lot to do with our attitudes.

The degree of our commitment to the principle of informed consent and the right to refuse treatment is most severely tested by those whose lives can be indefinitely prolonged by medical science but who judge that their pains of soul and/or body are and will be so unendurable that death is preferable to treatment. Such situations may be relatively rare, but they do occur. For example, young patients who are severely burned may have a good prospect for con- 
tinued life and even some semblance of health, but they may prefer to die rather than submit to excruciatingly painful and endlessly prolonged therapies and a significantly diminished quality of life [51]. Many other kinds of patients also choose to trade off great quantities of life in exchange for pain relief [52].

Although my view is controversial, I am convinced that patients in our second category have an extremely strong prima facie right to refuse treatment too painful to bear or which would prolong a life too painful to endure. May this basic right ever be justly overridden? Both the law and the enlightened moral conscience would I believe, recognize the following conditions which set aside or override the principle of informed consent and the right to refuse treatment:

(1) where the patient is in an emergency situation and is unconscious, confused or so overwhelmed by his immediate pain that he may be presumed not to be sufficiently rational to decide his ultimate fate;

(2) where the patient's condition presents a clear and present danger to others, either of violent assault or of serious communicable disease;

(3) where other persons, such as children, depend so heavily on the patient that the state has a compelling interest in preserving the patient's life, though here we might want to be sure that the most important of these responsibilities could not be met in some other way.

(4) where the patient is a minor, though here there is the borderline case of the exceptionally mature minor; and proxies may refuse treatment on grounds of unendurable pain, as they may in the following situation;

(5) where the patient is mentally incompetent to understand his own circumstances or incapable of making decisions;

(6) where sufficient efforts have not been made to insure that the patient is adequately informed, or where it appears that the patient is acting under duress. In other words, where it is not clear that the patient is capable of giving informed voluntary consent or refusal.

Given my utilitarian leanings in moral philosphy, I would like to add a final condition for consideration, though I am sure that those who attach absolute value to individual autonomy will promptly reject it after they consider it. Finally, a patient's refusal of treatment may be overturned;

(7) where a review committee [53] determines in conference and on the basis of a careful and impartial review of the patient's realistic prospects for suffering and for a meaningful future existence, that overriding his immediate wishes will be significantly less harmful in the long run to his essential interests than the suffering which he must endure. An example might be the case of a young and otherwise healthy burn patient who refuses treatment needed to save his life even though he will likely suffer from no permanent disfigurement or disability once treatment is conpleted.

Though the seventh condition will have only extremely rare applications, if any at all, and though the sixth condition may seem redundant, I believe that it is legitimate and highly desirable up to a point to challenge the patient's life endangering refusal to endure pain. In particular cases, the patient really may not be capable of knowing what he is doing or able to make that ideal decision which a 'reasonable person' would make; or he may be too susceptible to nonrational or coercive influences, such as pain itself or his awareness that his family wants him to die so they can inherit his fortune. Proper procedural safeguards for the protection of both the patient and the medical staff should always be provided. Also, the most objectionable features of blatant medical paternalism must be avoided by the introduction of a collective rational decision procedure designed to insure that any decisions reached will have the highest degree of objective and interpersonal validity which it is humanly possible to achieve. In applying the seventh criterion, the patient's own judgment must be given the benefit of every serious doubt, and only where it can be determined that the patient's essential interests will obviously be best protected by preserving life should a review committee decide to override. Appealing to a review committee will be especially useful where a patient does not want to submit to painful therapy but also does not want to dic, or where the patient's own attitudes are so ambivalent that they cannot be determined [54].

After proper allowances have been made for all the foregoing overriding conditions, a substantial number of cases will still remain in which no reasonable doubt can be sustained that the patient is acting freely, knowingly and rationally in refusing life prolonging therapy on the grounds that the life so prolonged will be unacceptably painful, both physically and/or mentally. Such a patient must be allowed to die, but no dying person should be allowed to suffer from such pains of soul as a sense of alienation from the human community or a fear of abandonment as the end comes. Those who refuse life saving therapy should still be offered any of the comforts of medication and the solace of the presence of medical personnel and loved ones that they will accept. The ethics of voluntary informed consent and refusal provides a clear ethical rationale for passive euthanasia in such instances. Though it is beyond the scope of this paper, it is quite possible that the ethics of pain relief further requires assistance in autoeuthanasia, and even active euthanasia, in extreme cases $[55]$.

\section{REFERENCES}

1. Oates W. J. (Ed.) The Stoic and Epicurean Philosophers pp. 49-50. The Modern Library, New York, 1940.

2. I critically discuss several of these which I find to be inadequate in: Edwards R. B. Pleasures and Pains: A Theory of Qualitative Hedonism. pp. 42-44. Cornell University Press, Ithaca, 1979.

3. For a more detailed explanation of this distinction, see Pleasures and Pains: A Theory of Qualitative Hedonism. Chap. 2. Although he regards the notion of mental pains as 'metaphorical, $H$. Merskey made much the same sort of phenomenological distinction between mental and physical pains when he wrote that "anguish. sorrow, misery, distress, etc. are not words which necessarily indicate any felt somatic disturbance. Mental pain is a different concept from pain and has to be kept separate". See Merskey H. Pain and personality. In The Psychology of Pain (Edited by Stermback R. A.) p. 112. Raven Press. New York. 1978. 
4. May R. Love and Will, p. 150. Dell, New York, 1969.

5. Fagerhaugh S. Y. and Strauss A. Politics of Pain Management, p. 47. Aḍdison-Wesley, Menlo Park, CA, 1977.

6. Ibid., p. 184

7. Ibid., p. 158 .

8. Edwards R. B. op. cit., pp. 73, 74, 86. Those who are really turned on by behavior could add 'behave' to 'desire' in this definition for all I care.

9. I suggest that this may not be true on the grounds that by the time our ancestors were sufficiently evolved to develop a pain vocabulary. they were also sufficiently evolved to experience and want to talk about both mental and physical pains.

10. Illich I. Medical Nemesis. p. 135. Bantam Books, New York, 1976

11. For some examples of this, see Fagerhaugh $\mathrm{S}$. Y. and Strauss A. op. cit.,pp. 24, 118, 146-147, 175-176, 280.

12. Ibid. This is especially true in the case of Mrs Abel. See Chap. 3, pp. 143-144, and p. 248.

13. I do not mean to suggest that such epicureans are like the followers of Epicurus in being exclusively devoted to the pursuit of pleasure and the avoidance of pain, or in being egoists. I mean merely that they are super sensitive to pain. In the section to follow. I also use 'stoic' in a modern rather than a historical sense.

14. See Fagerhaugh S. Y. and Strauss A. op. cit., p. 284 for this terminology.

15. Asenath Petrie A. Individuality in Pain and Suffering, p. 2. University of Chicago Press, Chicago, 1967.

16. Ibid.

17. Ibid., p. 1.

18. Ibid., pp. 1-2.

19. Ibid., Chap. 1, 2 and Appendices.

20. Ibid., p. 43.

21. Ibid., pp. 16-17.

22. Ibid., p. 24

23. Ibid., pp. 24-25.

24. Ibid., pp. 27, 88

25. Ibid., p. 88 .

26. Ibid., pp. 27-32, 72, 89-90.

27. Ibid., pp. 37,89

28. Ibid., p. 27

29. Ibid., pp. $28-30$.

30. Ibid., p. 44

31. Ibid., pp. 33-36, 44 .

32. Ibid., p. 36

33. Ibid., pp. 90.99.

34. Ibid., pp. 36, 101.
35. Ibid., p. 98.

36. Ibid., p. 89

37. Ibid., p. 105.

38. See Petrie's summary of some additional findings on $p$. 21.

39. Fagerhaugh S. Y. and Strauss A. op. cit. p. 124.

40. Ibid., p. 121 .

41. Ibid., p. 124

42. Ibid., p. 126.

43. The initial detailed study of Mrs Abel's case was published as: Strauss A. and Glaser B. Anguish Sociology Press, Mill Valley, CA, 1970.

44. Fagerhaugh S. Y. and Strauss A. op. cit. p. 122

45. Ibid., p. 121

46. Ibid., p. 122

47. Illich I. op. cit. Chap. 3, entitled 'The Killing of Pain'

48. Frankl V. E. The Doctor and the Soul, pp. 105-116. Vintage Books, New York, 1973.

49. Kaufmann W. (Ed.) The Portable Nietzsche, p. 31 Viking Press, New York, 1954. Nietzsche himself seemed to advocate such cruelty, however, in section 225 of his Beyond Good and Evil.

50. Veatch R. M. Death Dying and the Biological Revolution, p. 116. Yale University Press, New Haven, 1976.

51. For excellent discussions of burn patients and the special problems they raise see Fagerhaugh $S$. Y. and Strauss A. op. cit. Chap. 7. Also see Imbus S. H. and Zawacki B. E. Autonomy for burned patients when survival is unprecedented. New Engl. J. Med. 297, 308-311, 1977. For the much discussed Texas burn case see White R. B. and Englehardt H. T. Jr. Case studies in biocthics. Hastings Center Rep. 5, 9-10, 47, 1975.

52. For some interesting cases, see Fagerhaugh S. Y. and Strauss A. op. cit., p. 247.

53. I do not wish to be too specific about the formal constitution and composition of such a committee, but it might include medical professionals, family members, friends, and possibly other persons from the community who have no special interest in the case. Such a commit tee should attempt to apply the principle of 'retrospective gratitude'.

54. For a discussion of a number of troublesome cases in which the will of the patient is impossible to determine see: Jackson D. L. and Younger S. Patient autonomy and 'death with dignity': some clinical caveats. New Engl. J. Med. 301, 404-408, 1979.

55. For a discussion of some of these issues see Fagerhaugh S. Y. and Strauss A. op. cit. 